Engineering, Technology and Techniques

Vol.61: e18160520, 2018

http://dx.doi.org/10.1590/1678-4324-2018160520

ISSN 1678-4324 Online Edition

\title{
Influence of Ionizing Radiation on Biodegradable Foam Trays for Food Packaging Obtained from Irradiated Cassava Starch
}

\author{
Antônio Jedson Caldeira Brant ${ }^{1 *}$, Natália Naime ${ }^{1}$, Ademar Benévolo Lugão ${ }^{1}$, Patrícia \\ Ponce $^{1}$ \\ ${ }^{1}$ Instituto de Pesquisa Energéticas e Nucleares - Centro de Química e Meio Ambiente, São Paulo, São Paulo, \\ Brasil.
}

\begin{abstract}
Biodegradable polymers, such as starch, cellulose, and derivatives thereof, are being studied to produce innovative packaging in the most diverse shapes (films, bags, trays, bottles, etc.) to attend this current market trend. The aim of this work was to produce foam trays from cassava starch for food packaging via extrusion followed by thermoforming process. Their formulations were based on unirradiated and $\gamma$-irradiated starches at diverse radiation absorbed doses (in $k G y$ ) in order to evaluate the influence of the irradiated starches on the physical properties of the trays. Water absorption results showed an irregular increase with the increase of the absorbed dose ( for example, 26.32\% and $39.84 \%$ for the trays based on unirradiated starch $0 k G y$ and $1: 1(w / w)$ mixture of starches 0 kGy and 100.0 kGy, respectively). Other physicochemical properties were evaluated from the starches utilized and the trays obtained. Aerobic biodegradation of the foams by mass loss also was checked in soil burial test.
\end{abstract}

Keywords: biodegradable foam; cassava starch; food packaging; ionizing radiation

*Author for correspondence: thonybrant@gmail.com 


\section{INTRODUCTION}

Nowadays, the disposal of nonbiodegradable plastic materials is scary, especially in large urban centers. According to Atiq et al. (1), "millions of tons of solid waste are disposed off annually in the world and a large proportion consists of plastics". Strictly speaking, plastics are polymeric materials which, in their majority, originate from nonbiodegradable synthetic polymers. Such polymers from petrochemical sources can take from a few up to several hundreds of years to decompose naturally $(2,3)$. So, despite of the great benefits that the synthetic polymers have afforded to mankind in all application fields (packaging, furniture, components or structures of cars, planes, electric and electronic equipment, civil building, and many others), their waste, however, has become a great environmental threat all over the world (4).

In the last two decades, there has been an increase of commercial and academic interest in synthesizing or developing biodegradable polymers, mainly to produce packages from renewable resources. Biodegradable polymer is every natural or synthetic polymer that can be decomposed by microorganisms (bacteria, fungi, algae) in favorable environments in terms of temperature, aeration, humidity, and other conditions. Its total decomposition leads to release of $\mathrm{CO}_{2}$ and $\mathrm{H}_{2} \mathrm{O}$ molecules and formation of a biomass over a specific period of time $(5,6)$. Biodegradable packaging, despite having some use limits, could be at least a good alternative to lessening the environmental impact of solid waste on the planet.

Among the natural polymers from renewable sources, cellulose and starch, as well as their respective derivatives, have encountered growing interest in the use of them in package manufacturing. However, both polysaccharides have poor mechanical properties and are quite hydrophilic to be straightly employed as packaging in any shape (film, bottle, cup, tray, others) $(7,8)$. Development and production of starchbased trays to replace those from expanded polystyrene (EPS) for food packaging constitute an innovative subject that appears to be promising $(9,10,11)$. Nevertheless, several challenges related to the trays' quality may emerge due to various chemical and physical properties inherent to native starch, for instance, its high water absorption. This implies in a poor barrier property for its use as packaging for food.

Starch is a mixture of linear and branched 1,4- $\alpha$-D-glucopyranose biopolymers, called amylose and amylopectin, respectively. Amylose is an essentially linear $(1 \rightarrow 4)$-linked $\alpha$-D-glucan, whereas amylopectin is a highly branched macromolecule consisting of short chains of $(1 \rightarrow 4)$-linked $\alpha$-D-glucose with $(1 \rightarrow 6)$ - $\alpha$-linked branches $(12)$. This polymer originates from various renewable resources (potato, rice, corn, cassava, arrowroot, others), and its use encompasses foods, drug encapsulation, paper adhesives, textile sizing, and in many other applications.

Corn starch and its derivatives have been used in the development of biodegradable disposable packaging materials, such as domestic and commercial utensils in the most varied shapes - films and trays for food packaging, plastic containers, cups, tableware, etc. (13). Hence, several patents $(14,15,16)$ and numerous scientific papers on this subject have been published so far. However, performance of any starch as structural polymer or coating/film depends upon the ratio of amylase/amylopectin, which plays an important role in the swelling of the granules and the formation of a continuous phase during its gelatinization $(12,17)$ as well as in the retrogradation of this natural polymer $(18,19)$. Moreover, it usually needs addition of water (a natural plasticizer) or other kinds of plasticizers, such as glycols, urea, etc. to be subsequently processed by extrusion, injection or thermoforming.

Exposure of polymers to ionizing radiation ( $\gamma$-rays, X-rays, accelerated electrons, ion beams) may induce formation of many very reactive intermediates, free radicals, ions, 
and excited states (20), whose fates involve numerous chemical reactions, even after stopping the irradiation process. Chain scission without recombination of free radicals leads to degradation of polymers, and hence lowering of their molecular weights. On the other side, crosslinking can occur when macroradicals recombine each other to form a tridimensional polymer network of molecular weight approaching infinity (21), becoming an infusible material, also insoluble in any solvent. Both chemical processes are competitive and take place simultaneously. Generally, one of these reactions will prevail over the other, and the irradiated polymer surely will have physicochemical characteristics distinct from the original ones.

Effects of ionizing radiation on polymers are a subject of increasing interest in research and development of novel polymeric materials once their chemical and physical properties can be quite affected by induction of crosslinking and/or degradation reactions, crystallinity degree changes, isomerization, etc. $(22,23,24)$. In relation to starch, this polymer undergoes breaking of its glycosidic bonds, that is, degradation $(25,26,27)$, besides having possible modifications of its crystalline structure. Thus, many of starch physicochemical properties may be changed depending on the total radiation dose absorbed by the polymer $(28,29)$. According to Kiatkamjornwong et al. (30), $\gamma$-rays produce free radicals at the active site of C-2 or C-3 (both contain hydroxyl group) of the starch backbones, where those researchers carried out grafting of poly (acrylic acid) and polyacrylamide. Literature concerning starch films for food packaging also has reported increase of their tensile strength and barrier properties after subjected to ionizing radiation exposure $(31,32)$.

The aim of this work was to produce, by extrusion-thermoforming process, biodegradable foam trays from cassava (Manihot esculenta Crantz) starch for food packaging. This biopolymer is very cheap and abundant in Brazil. The trays' formulations were mainly based on mixtures of unirradiated starch with irradiated starch at diverse $\gamma$-irradiation doses.

\section{MATERIALS AND METHODS}

\section{Materials}

Cassava starch powder (from Lorenz - Paraná State - Brazil) with ca. 18\% of amylose and ca. $82 \%$ of amylopectin, water content: $13.45 \pm 0.22$; glycerol (Labsynth - São Paulo - Brazil); water.

\section{Methods}

\section{Starch irradiation}

Cassava starch powder was irradiated at absorbed doses of 25.0, 50.0, and $100.0 \mathrm{kGy}$ on a sealed ${ }^{60} \mathrm{Co}$ source of $\gamma$-rays at EMBRARAD (Cotia - SP - Brazil) with an absorbed dose rate of $5.0 \mathrm{kGy} \mathrm{h}^{-1}$ in presence of air at room temperature $\left(\mathrm{ca} .25^{\circ} \mathrm{C}\right.$ ).

\section{Batter preparation}

Batches of $3.0 \mathrm{~kg}$ of each formulation were prepared by mixing $40 \%$ of unirradiated starch and $40 \%$ of $\gamma$-irradiated starch by weight, followed by addition of $19 \%$ of tap water and $1 \%$ of glycerol. For this operation a stainless-steel mixer (from $\mathrm{MH}$ Equipamentos Ltda, Guarulhos - SP - Brazil) of 8.0 L capacity was used, equipped of a double helice, and working for $3 \mathrm{~min}$ at $1100 \mathrm{rpm}$ at room temperature (RT). As reference, only unirradiated starch $(80 \%, \mathrm{w} / \mathrm{w})$ was used together with the same components of the mixtures containing the $\gamma$-irradiated starches.

pH measurements of unirradiated and irradiated starches 
Aqueous starch suspensions of $10.0 \mathrm{~g}$ of each starch type/90.0 $\mathrm{g}$ of deionized water were prepared under mechanical stirring at environmental conditions during ca. 10 min. Next, they were left to rest for $30 \mathrm{~min}$. Thereafter, the $\mathrm{pH}$ measurements of triplicates of the suspensions were carried out at $23^{\circ} \mathrm{C}$ by using a digital microprocessor $\mathrm{pH}$ meter from Hanna Instruments, model HI 221 (Brazil), equipped with a temperature sensor, previously calibrated with buffer solutions of $\mathrm{pH} 4.00$ and $\mathrm{pH} 7.00$.

Rheological properties: starch apparent viscosity

For measuring viscosities of irradiated and unirradiated starches, starch gels were prepared dispersing $4.0 \mathrm{~g}$ the starch in $96.0 \mathrm{~g}$ of distilled water. Next, the starch suspensions were placed on a heating plate at $90^{\circ} \mathrm{C}$ under mechanical stirring for 30 min. The gel and starch suspensions obtained were cooled to RT (ca. $25^{\circ} \mathrm{C}$ ) and allowed to rest for one day in order to eliminate their internal bubbles. Afterwards, their viscosities were measured by using a Brookfield viscometer, model LV (spindles SC 4-18 and SC 4-34) at $28^{\circ} \mathrm{C}$, which displays results in $\mathrm{cP}(=\mathrm{mPa} \mathrm{s})$.

Attenuated total reflectance (ATR) - Fourier transform infrared spectroscopy (FTIR) ATR-FTIR spectra of unirradiated and irradiated starches were acquired on a Thermo- Nicolet Nexus 670 FT-IR spectrophotometer. Powder starch samples were fixed on the ATR accessory, and the spectra were recorded in the range from $4000-$ $450 \mathrm{~cm}^{-1}$ wavenumbers at room temperature, with a resolution of $2 \mathrm{~cm}^{-1}$ and 64 scans.

\section{Tray molding}

Extrusion of the batters (from 2.2.2.) was performed on a single-screw extruder (built by GFC Indústria e Comércio Ltda., São Paulo - SP) equipped with 3 heating zones $\left(60{ }^{\circ} \mathrm{C}, 80{ }^{\circ} \mathrm{C}, 90{ }^{\circ} \mathrm{C}\right)$, at $0-100 \mathrm{rpm}$ and a frequency of $25 \mathrm{~Hz}$. Afterwards, the extrudate - 65.00-75.00 g for the control, i.e. based on unirradiated starch, and ca. $60.00 \mathrm{~g}$ for those based on the two starch types - was thermoformed on an appropriate Teflon-coated stainless-steel mold at $190-195^{\circ} \mathrm{C}$ and ca. $1 \mathrm{MPa}$ for $80 \mathrm{~s}$. The obtained trays were identified as Bj-St 0 kGy, Bj-St 25 kGy, Bj-St 50 kGy, Bj-St 100 kGy.

\section{Compression strength and flexibility}

After production, the foams were conditioned at $23^{\circ} \mathrm{C}$ and $60 \% \mathrm{RH}$ (air relative humidity) for 3 days before mechanical testing. They were cut into rectangular shapes $(10 \mathrm{~cm} \times 4 \mathrm{~cm})$, being 6 specimens of each formulation. For this assay, a TA.XT2i texture analyzer from Stable Micro Systems was used, equipped with a cylindrical probe of $36 \mathrm{~mm}$ diameter and an annular support of $63 \mathrm{~mm}$ diameter. The compression speed was $1.00 \mathrm{~mm} / \mathrm{s}$ with a trigger force of $25 \mathrm{~g}$. The final results were taken as the numerical mean of each six-specimen set and expressed in compression strength $(\mathrm{N})$ and displacement of the probe up to the specimen rupture $(\mathrm{mm})$, i.e. distance/flexibility.

\section{Barrier properties of the foams - water absorption}

After production, the foam trays selected for barrier testing were conditioned at ca. $23^{\circ} \mathrm{C}$ and $60 \% \mathrm{RH}$ for at least 3 days. In this testing, each tray was weighed; next, $300 \mathrm{~mL}$ of distilled water were poured on it, and the system (tray - water) was kept for $10 \mathrm{~s}$ at room temperature. After this period, water was removed from the tray, and this was quickly dried by using an absorbent dry cloth and weighed again. Two samples were used per each formulation. The amount of water absorbed by the foam was calculated by Equation 1: 
Water absorption $(\%)=\frac{m_{\mathrm{h}}-m_{\mathrm{d}}}{m_{\mathrm{h}}} \times 100$

where: $m_{\mathrm{h}}=$ wet mass and $m_{\mathrm{d}}=$ dry mass. The final results were taken as the numerical mean of the sample sets.

\section{Density and thickness}

In this test, specimens in triplicate of each formulation were used, each of them with a $16 \mathrm{~cm}^{2}$ area and variable thickness $(\mathrm{cm})$, after previously conditioned at ca. $23^{\circ} \mathrm{C}$ and ca. $60 \%$ RH for 3 days. Thickness measurements were performed by using a Mitutoyo digital micrometer. Density was determined from the ratio of mass/volume (weighed on a digital analytical scale with the precision of $0.001 \mathrm{~g}$ ). The final result $\left(\mathrm{g} / \mathrm{cm}^{3}\right)$ for each formulation was taken as the numerical mean of the results of the corresponding triplicate.

\section{Scanning electron microscopy (SEM)}

SEM testing was performed by using a microscope Tabletop Hitachi, model TM3000. Micrographs of cross-section surfaces of starch foam tray specimens were obtained without use of sputter coating process, at an accelerating electron voltage of $15 \mathrm{kV}$ and magnifications of $150 \mathrm{x}$.

\section{Aerobic biodegradation by mass loss}

Biodegradability testing was performed based on the soil burial test. Two rectangular $(5.0 \mathrm{~cm} \times 7.0 \mathrm{~cm} \times 0.3 \mathrm{~cm}$ ) samples of each formulation (foams), previously weighed, were separately buried in $500.0 \mathrm{~g}$ of a simulated soil (earth + sand + cow manure) kept inside beakers duly identified. The beakers containing the foams fully buried in the soil were stored in a closet with air circulation and temperature control $\left(19^{\circ} \mathrm{C}\right.$ to $21^{\circ} \mathrm{C}$ ) at an air relative humidity (RH) from $70 \%$ to $78 \%$. After this procedure, every 7 days the samples were dug up, cleaned, weighed on a digital scale, and usually photographed for a better control until extensive degradation of the polymer has occurred. To compensate losses of the soil moisture (ca. 65\%) by evaporation in this open system, $50.0 \mathrm{~g}$ of distilled water were added to the soil after the samples' evaluation and for the continuity of the soil burial tests. The mean mass loss (in \%) of each duplicate was calculated for each foam formulation using Equation 2:

Mass loss $(\%)=\left[\left(m_{\mathrm{i}}-m_{\mathrm{f}}\right) / m_{i}\right] \times 100$

where $m_{\mathrm{i}}$ is the initial mass of the sample at the initial day and $m_{\mathrm{f}}$, the final mass of the sample measured at every 7 days. On the 42 nd day, the samples, after having been duly cleaned, were weighed and placed in a drying oven at $70^{\circ} \mathrm{C}$ for $24 \mathrm{~h}$. Thereafter, they were weighed again for calculation of their actual mass losses.

Note: Linear regression from mean mass loss results in biodegradation of starch foam trays was processed by using software from http://www.mathportal.org/calculators/statistics-calculator/correlation-and-regression-calculator.php and http://www.xuru.org/rt/toc.asp. One-way analysis of variance (ANOVA) and Tukey's HSD (honestly significant difference) post hoc tests were performed on the groups' data, and $p$-value $<0.05$ was considered as statistically or nonstatistically significant (confidence interval of $95 \%$ ) by using affordable online software: Interactive Statistics (http://statpages.info/anova1sm.html). We have emphasized the main results of one-way ANOVA showing the $F$ statistic and $p$-value. $F$-statistic or $F$-value is the ratio calculated by dividing the mean squares for the model $\left(\mathrm{MS}_{\mathrm{M}}\right)$ by the residual mean squares $\left(\mathrm{MS}_{\mathrm{R}}\right.$ ), or simply, $F=\mathrm{MS}_{\mathrm{M}} / \mathrm{MS}_{\mathrm{R}} . F$ has been represented followed by two integer numbers inside parentheses and separated by comma, where the first one is $\mathrm{df}_{1}$, that is, the degree of freedom related to variation between the number of sample groups, $k$, thus resulting in $k-1$; the second one is $\mathrm{df}_{2}$, that is, the degree of freedom related to variation within the samples comprising the total number of observations or total number of samples, $n_{\mathrm{t}}$, minus the total number of sample groups, $k$, resulting, therefore, in $n_{\mathrm{t}}-k$. For example, $F(3,16)$ means: $3=4$ sample groups minus $1(=k-1)$ and $16=20$ samples tested minus 4 sample groups $\left(=n_{\mathrm{t}}-k\right)$ from 
ANOVA evaluation, respectively. After the ANOVA's tests, multiple comparisons (Tukey's tests) were processed affording each $p$-value between two different groups tested pairwise.

Note: In samples' identification, starch was codified as $\mathrm{St}$ and $\mathrm{Bj}$, as tray.

\section{RESULTS AND DISCUSSIONS}

\section{pHs of Aqueous Starch Suspensions}

Table 1 shows the results of $\mathrm{pH}$ measurements of the aqueous starch suspensions. By increasing the irradiation dose, there was a trend of decreasing $\mathrm{pH}$ of the starch suspensions, mainly registering an abrupt fall of $\mathrm{pH}$ in that prepared with $100 \mathrm{kGy}$ starch. Functional groups (for example, carbonyl and carboxyl), eventually generated in chain scission of the polymer, may be the factors responsible for this $\mathrm{pH}$ decrease $(33,34)$. Formation of such functional acidic groups is also influenced by the exposure to oxygen during irradiation (35).

Table $1 \mathrm{pHs}$ of aqueous suspensions (10.0 $\mathrm{g}$ of starch / $90.0 \mathrm{~g}$ of deionized water at $23^{\circ} \mathrm{C}$ ) of unirradiated and irradiated cassava starches (Sts)

\begin{tabular}{ll}
\hline \multirow{2}{*}{ Absorbed dose (kGy) } & $\begin{array}{l}\text { pH } \\
\text { Mean } \pm \text { SD }\end{array}$ \\
\hline 0 & $5.13 \pm 0.11^{\mathrm{a}}$ \\
25 & $4.18 \pm 0.17^{\mathrm{b}}$ \\
50 & $3.95 \pm 0.15^{\mathrm{b}}$ \\
100 & $3.31 \pm 0.11^{\mathrm{c}}$ \\
\hline
\end{tabular}

$S D=$ standard deviation

Different superscript letters within the column indicate statistically significant mean difference among $\mathrm{pH}$ results according to one-way ANOVA and Tukey's HSD tests at $p<0.05$ and a confidence interval (CI) of $95 \%$.

ANOVA test from the results in Table 1 showed that the differences among the mean $\mathrm{pH}$ results, influenced by irradiation dose absorbed by starch, were statistically significant with an $F(3,8)=90.3003$ and a $p$-value $=0.0000$. However, Tukey's HSD (honestly significant difference) post hoc test showed a nonstatistical significance between $\mathrm{pH}$ of St-25 kGy and $\mathrm{pH}$ of St-50 kGy, that is, at $p=0.2478$, a 95\% CI.

\section{Rheological Properties of Starch Gel and Suspensions}

The profiles of the rheological curves displayed in Figures 1 and 2 indicate shearthinning effect on starch gel and suspensions. 


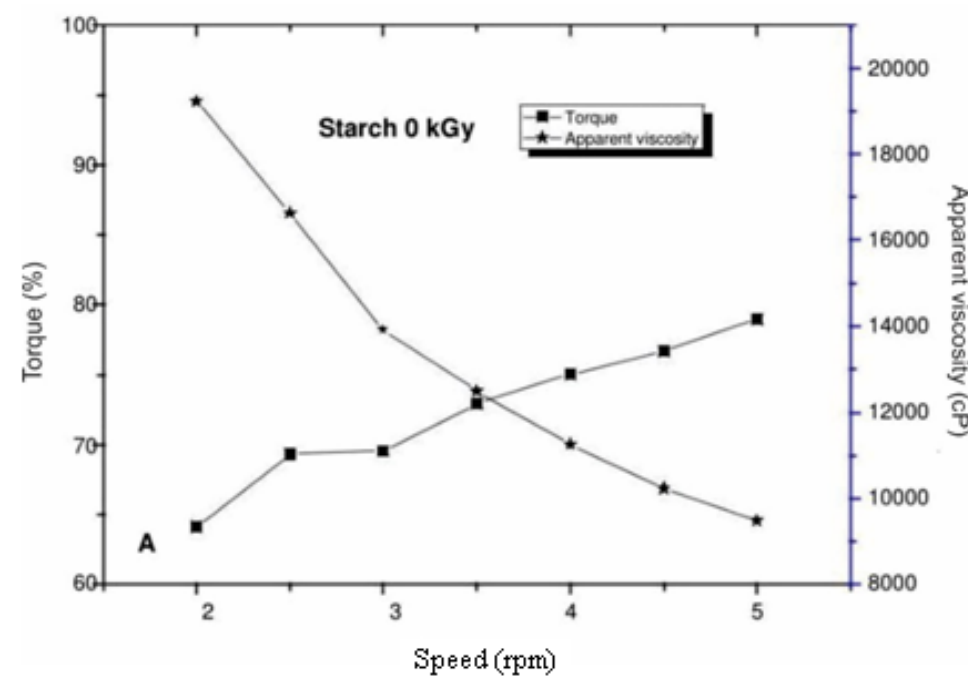

Figure 1- Rheology of the gel from unirradiated starch dispersed in distilled water (4\%, w/w). Measurements of torque ( $\mathbf{\square})$ and apparent viscosity $(1 \mathrm{cP}=1 \mathrm{mPa} \mathrm{s})(\star)$ made on a Brookfield viscometer, model LV, spindle SC 434 , at $28^{\circ} \mathrm{C}$. Time: after $10 \mathrm{sec}$ for each register.

The gel of the unirradiated starch ( $0 \mathrm{kGy})$ exhibited high torque and high viscosity, whereas the starch suspensions from the mixtures behaved on the contrary, what is in accordance with the physical laws relating to viscous fluids. Viscosity lowering of $\gamma$ irradiated starch may have occurred owing to its degradation, chiefly causing breaking of amylopectin chains and degrading glycosidic linkages together with breaking of inter- and intramolecular hydrogen bonds of starch. Thus, viscosity diminished with the increase of the irradiation dose. Such a fact has also been reported by several researchers $(36,37,38)$.

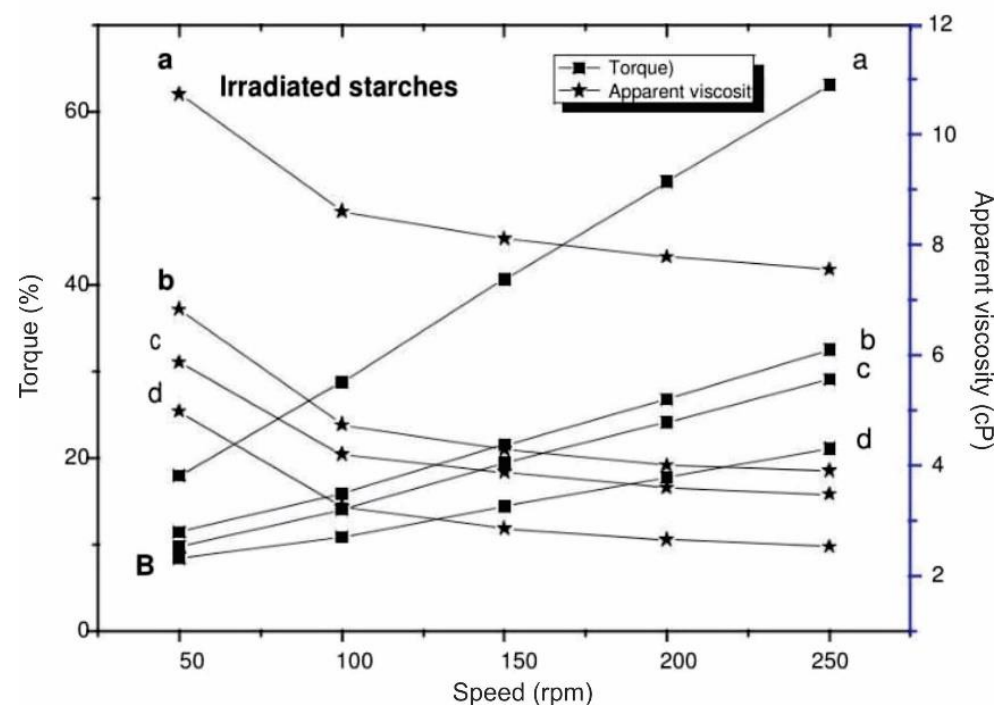

Figure 2- Rheology of suspensions of $\gamma$-irradiated starch (a- St 25 kGy; b-St 50 kGy; c -St 100 kGy) dispersed in distilled water $(4 \%, \mathrm{w} / \mathrm{w})$. Measurements of torque $(\mathbf{m})$ and apparent viscosity $(\star)(1 \mathrm{cP}=1 \mathrm{mPa} \mathrm{s}) \mathrm{made}$ on a Brookfield viscometer, model LV, spindle SC $4-18$, at $28^{\circ} \mathrm{C}$. Time: after $10 \mathrm{sec}$ for each register.

Attenuated total reflectance (ATR) - Fourier transforms infrared spectroscopy (FTIR)

The profiles of IR vibrational spectra of unirradiated and irradiated starches (Fig. 3) did not show significant differences among them. Evidently, the region between 3000 
and $3600 \mathrm{~cm}^{-1}(\mathrm{O}-\mathrm{H}$ stretch region) was registered. One must mention here the hydroxyl groups of the starch (at C-2, C-3, and C-6) as well as that of water in the samples. Usually, three states of water are present in matrices of hydrophilic polymers: (a) nonfreezable bound water, (b) freezable bound water, and (c) free water (39). Thus, total removal of water from hydrophilic polymers is very difficult even after prolonged drying in an aerated oven at $105-110^{\circ} \mathrm{C}$. Hence, water can interfere with the band resolution of group $\mathrm{O}-\mathrm{H}$ vibration (band broadening) observed in the IR spectra of such polymers. The region between 2800 and $3000 \mathrm{~cm}^{-1}$ (a shoulder indicating $\mathrm{C}-\mathrm{H}$ stretch region), was also registered. The characteristic band of starch at ca. $1000 \mathrm{~cm}^{-1}$ clearly appeared, and it refers to C-O-H bending. Other vibration bands also are pointed out in Figure 3. However, the skeletal mode vibration of glycosidic linkage $\left(900-950 \mathrm{~cm}^{-1}\right)$ of the polysaccharide (40) showed itself rather noisy, chiefly in the starch sample irradiated at $50 \mathrm{kGy}$. Probably, a better resolution would have been attained using sample discs from the starch powder dispersed in $\mathrm{KBr}$, and compressed afterwards.

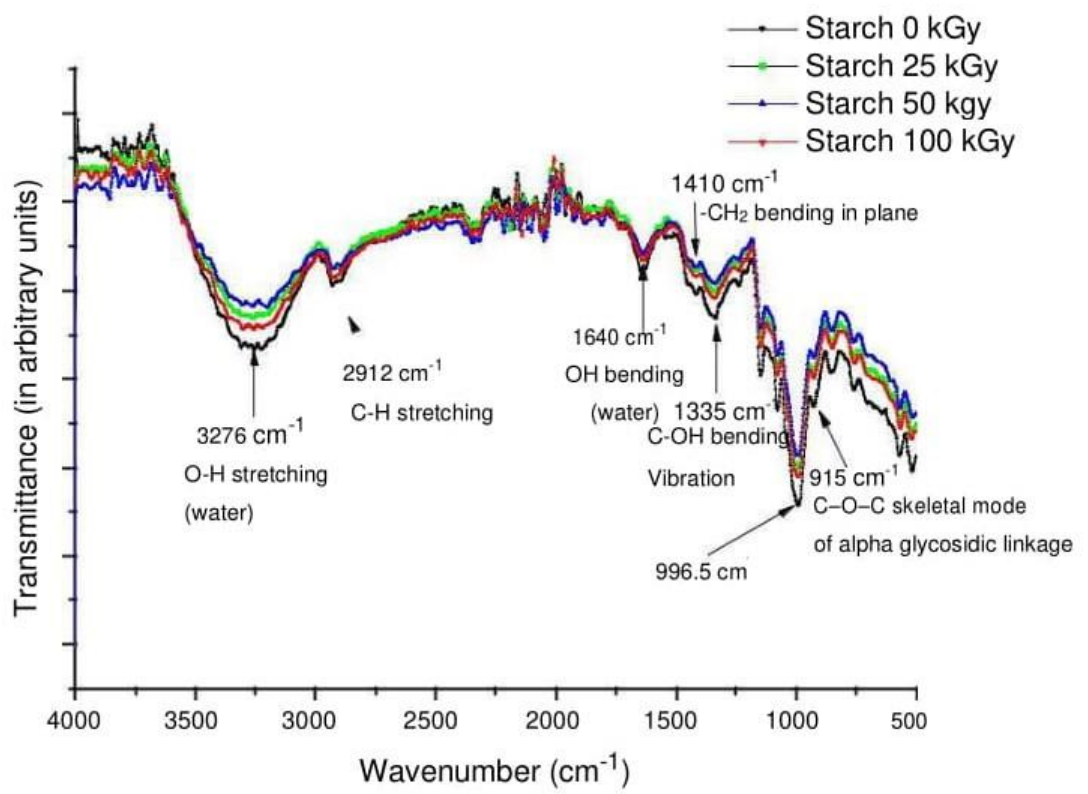

Figure 3-ATR-FTIR spectra of unirradiated cassava starch $(\mathrm{St})$ and $\gamma$-irradiated cassava starch at diverse $\gamma$-radiation absorbed doses.

\section{Processability of the Batters and Appearance of the Trays}

Extrusion processability of the batters based on starch mixtures appeared to be easier than that of the batter containing only unirradiated starch, probably thanks to degradation of polymer by $\gamma$-radiation, enhanced by shear forces in the extrusion zones and heat inherent to the thermoforming process. These three events can result formation of parcels of low-molecular weight starches in the batters. Concerning appearance of the trays, some rough spots on their surfaces caused by bubble bursting were observed (Figure 4), mainly on those from starch mixtures, which also showed stronger trends in yellowing. The latter also may occur according to Bhat and Karim (41), due to probable changes in molecular structure of starch after chain radiolysis or oxidative reactions caused by noninert atmosphere throughout radiolysis. Moreover, the extrusion-thermoforming process can also lead to formation of low-molecular weight products either from Maillard reactions of starchy products, especially in foods, whose chemistry is extremely complex (42), or by starch hydrolytic degradation, for example, formation of pyrodextrins, which probably may contribute to that yellowing $(43,44)$. 


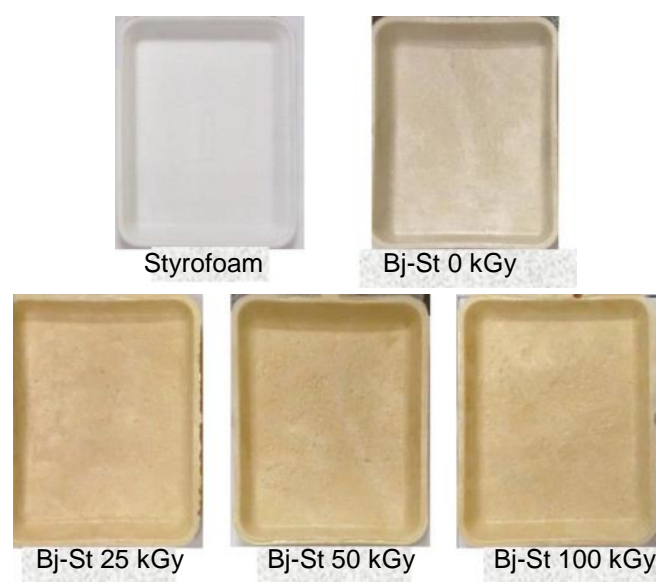

Figure 4-. Appearance of trays molded from mixtures of unirradiated and $\gamma$-irradiated cassava starches compared to that of a styrofoam tray from Brazilian market.

\section{Compression Strength - Flexibility}

Compression strength and flexibility (= distance run by the probe up to sample rupture) clearly diminished under influence of $\gamma$-irradiated starch (50\% by weight) at increasing radiation absorbed dose (Table 2 ).

Table 2- Results of compression strength (N) and flexibility/ distance (mm) of starch tray samples, measured at $23 \pm$ $2^{\circ} \mathrm{C}, \mathrm{RH} 60 \%$

\begin{tabular}{ccc}
\hline & $\begin{array}{c}\text { Compression strength }(\mathrm{N}) \\
\text { Mean } \pm \mathrm{SD}\end{array}$ & $\begin{array}{c}\text { Flexibility/distance (mm) } \\
\text { Mean } \pm \text { SD }\end{array}$ \\
\hline Bj-St 0 kGy & $33.01 \pm 0.84^{\mathrm{a}}$ & $10.24 \pm 0.28^{\mathrm{a}}$ \\
Bj-St 25 kGy & $26.17 \pm 3.34^{\mathrm{b}}$ & $10.35 \pm 0.19^{\mathrm{a}}$ \\
Bj-St 50 kGy & $19.22 \pm 0.71^{\mathrm{c}}$ & $6.64 \pm 0.08^{\mathrm{b}}$ \\
Bj-St 100 kGy & $16.44 \pm 2.08^{\mathrm{c}}$ & $5.74 \pm 0.17^{\mathrm{c}}$ \\
\hline
\end{tabular}

$S D=$ standard deviation

Different superscript letters in each column indicate a significant difference among mean results of compression strength likewise between those of flexibility according to one-way ANOVA and Tukey's HSD tests at $p<0.05$ and a confidence interval (CI) of $95 \%$.

The results in Table 2 suggest predominance of chain backbone scission and internal crystallinity changes of the polymer submitted to $\gamma$-radiation together with a partial degradation of starch components in the extrusion process (45). There was also a trend of diminishing the flexibility of the samples (except for Starch $25 \mathrm{kGy}$ ) with addition of irradiated starches, and this trend was proportional to the radiation absorbed dose. Interestingly, according to Sriroth et al. (46), results of tensile strength and elongation at break of foams obtained from a blend of starch-poly( $\varepsilon$ caprolactone) (PCL), 30:70 w/w, respectively, also dropped off with the use of $\gamma$ irradiated granular starch in the mixture. Thus, before irradiated, the tensile strength was $16.5 \mathrm{MPa}$ and elongation at break, $403 \%$; after irradiated, $12.0 \mathrm{MPa}$ and $383.6 \%$, respectively.

According to one-way ANOVA technique from the results in Table 2, compression strength exhibited an $F(3,20)=79.3470$ and $p=0.0000$, suggesting that the differences in the mean results were statistically significant at a $95 \%$ CI. However, Tukey's HSD (Honestly Significant Difference) post hoc test showed nonsignificance 
between compression strengths of $\mathrm{Bj}-\mathrm{St}-50 \mathrm{kGy}$ and $\mathrm{Bj}-\mathrm{St}-100 \mathrm{kGy}$, that is, $p=$ 0.1185 at a $95 \%$ CI. In relation to flexibility results submitted to the above cited statistical technique, the obtained values were: $F(3,20)=921.8732$ and $p=0.0000$; however, Tukey's HSD post hoc test displayed only a statistically significant $p$-value: $p=0.0000$ between $\mathrm{Bj}$-St $50 \mathrm{kGy}$ and $\mathrm{Bj}$-St-100 kGy; the other pairwise $p$-values were $>0.05$.

\section{Barrier Properties of the Foams - Water Absorption (\%)}

Results in Table 3 show an increase of water absorption with the increase of radiation dose absorbed by starch. It is an indicative of a growing presence of glycoside oligomers and other low-molecular weight products formed after the polymer having been $\gamma$-irradiated. The irradiated polymer tends to become more hydrophilic or hydrosoluble than the unirradiated one. Subsequently, throughout the extrusion under high shear forces and further thermoforming process of the starch batters, it is also possible to form such low-molecular weight products owing to degradation (47). Moreover, one has to consider the presence of large and open cells with ruptured walls, slightly increasing with the increase of the radiation absorbed dose as shown in Figure 5 (SEM). They in turn constitute sites of high water absorption.

Table 3- Water absorption of foam trays, molded from mixtures of unirradiated and $\gamma$-irradiated cassava starches

\begin{tabular}{cc}
\hline Tray sample & Water absorption at RT (\%) \\
& Mean $\pm S D$ \\
\hline Bj-St 0 kGy & $26.32 \pm 1.19^{\mathrm{b}}$ \\
Bj-St 25 kGy & $30.83 \pm 1.57^{\mathrm{b}}$ \\
Bj-St 50 kGy & $44.29 \pm 3.78^{\mathrm{a}}$ \\
Bj-St 100 kGy & $39.84 \pm 0.00^{\mathrm{a}}$ \\
\hline
\end{tabular}

RT: room temperature of $23 \pm 2^{\circ} \mathrm{C} ; S D=$ standard deviation.

Different superscript letters within the column indicate significant differences in data sets according to one-way ANOVA and Tukey's HSD tests at $p<0.05$ and a confidence interval (CI) of $95 \%$.

About water absorption, one-way ANOVA test from the results in Table 3 displayed an $F(3,4)=29.6543$ and a $p$-value $=0.0034$, indicating that the difference among the mean results of water absorption were statistically significant at a 95\% CI and straightly depending on the $\gamma$-irradiation dose to which starch was exposed. However, Tukey's HSD post hoc test showed no statistical significance between Bj- St 0 kGy and $\mathrm{Bj}$-St $25 \mathrm{kGy}$, and between Bj-St $50 \mathrm{kGy}$ and $\mathrm{Bj}-\mathrm{St} 100 \mathrm{kGy}$, that is, $p$-values of 0.2878 and 0.2957 at a $95 \% \mathrm{CI}$, respectively.

\section{Density and Thickness}

Table 4 shows results of a decrease of density and an increase of the trays' thickness with increasing the radiation dose.

Table 4- Density and thickness of trays molded from mixtures of unirradiated and $\gamma$-irradiated cassava starches at 23 $\pm 2{ }^{\circ} \mathrm{C}$ and $60 \pm 2 \% \mathrm{RH}$ (air relative humidity)

\begin{tabular}{ccc}
\hline Tray sample & $\begin{array}{c}\text { Density }\left(\mathrm{g} \mathrm{cm}^{-3}\right) \\
\text { Mean } \pm S D\end{array}$ & $\begin{array}{c}\text { Thickness }(\mathrm{mm}) \\
\text { Mean } \pm S D\end{array}$ \\
\hline Bj-St 0 kGy & $0.21 \pm 0.02^{\mathrm{a}}$ & $0.288 \pm 0.006^{\mathrm{b}}$ \\
Bj-St 25 kGy & $0.19 \pm 0.01^{\mathrm{b}}$ & $0.309 \pm 0.004^{\mathrm{a}}$ \\
Bj-St 50 kGy & $0.18 \pm 0.02^{\mathrm{b}}$ & $0.323 \pm 0.004^{\mathrm{a}}$ \\
Bj-St 100 kGy & $0.16 \pm 0.01^{\mathrm{c}}$ & $0.312 \pm 0.002^{\mathrm{a}}$ \\
\hline
\end{tabular}

$S D=$ standard deviation.

Different superscript letters within the column indicate significant differences in data sets according to one-way ANOVA and Tukey's HSD tests at $p<0.05$ and a confidence interval (CI) of $95 \%$. 
The density exhibited an inverse behavior: a decrease with increasing the radiation dose absorbed by the polymer system. It suggests a higher swelling of the mixtures due to the increase of hydrophilicity and lowering of crystallinity of the irradiated starches present in them, hence leading to a bigger expansion of the trays in the thermoforming process. In relation to the thickness, radiations doses of $25 \mathrm{kGy}$ and $100 \mathrm{kGy}$ showed very close values.

In relation to tray density, $F(3,8)=5.2000$ and $p=0.0277$, obtained by one-way ANOVA technique, indicate that the mean difference among the results in Table 4 is statistically significant at $p<0.05$ and a $95 \% \mathrm{CI}$ in function of the irradiation dose to which starch was exposed; however, post hoc Tukey HSD test showed statistically significant mean differences only between Bj-St $0 \mathrm{kGy}$ and $\mathrm{Bj}-\mathrm{St} 100 \mathrm{kGy}(p=$ 0.0198). The mean differences between the other pairwise tested groups were not statistically significant. In relation to the tray thicknesses, ANOVA displayed $F(3,8)$ $=35.6667$ and a $p$-value $=0.0001$, showing that the mean difference among the results is statistically significant at a 95\% CI; but, Tukey's HSD post hoc test displayed a $p$-value $=0.8220$ between Bj-St $25 \mathrm{kGy}$ and $\mathrm{Bj}-\mathrm{St} 100 \mathrm{kGy}$ and a $p$-value $=0.0519$ between $50 \mathrm{kGy}$ and $100 \mathrm{kGy}$, indicating that their mean differences in results are not statistically significant at a $95 \% \mathrm{CI}$.

\section{Scanning Electron Microscopy (SEM)}

Figure 5 displays photomicrographs samples of trays (cross-sections of $150 \mathrm{x}$ magnitude) molded from unirradiated starch $(\mathrm{Bj}-0 \mathrm{kGy})$ and from mixtures of this and $\gamma$-irradiated starches (Bj-25 kGy, Bj-50 kGy, and Bj-100 kGy), where large and open cells with ruptured walls were formed during water vapor expansion, which increases the pressure inside the mold.

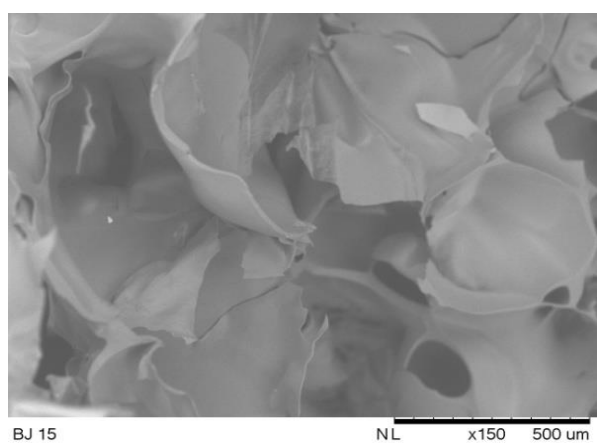

A

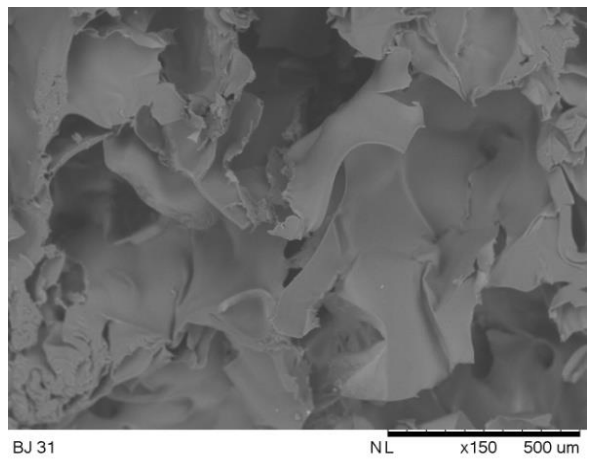

C

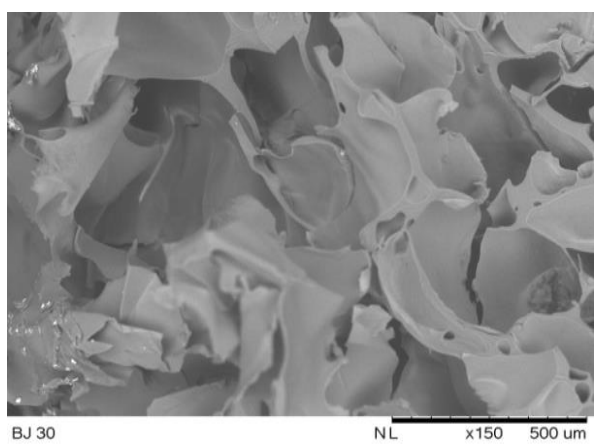

B

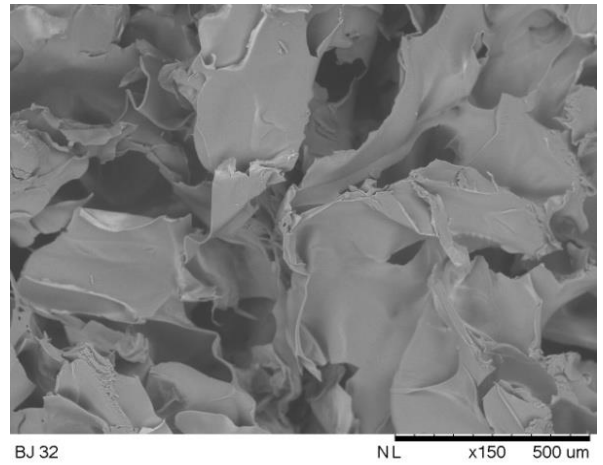

D

Figure 5-. SEM microphotographs of starch tray cross-sections: A) Bj-St 0 kGy; B) Bj-St 25 kGy; C) Bj-St 50 kGy; and D) Bj-St $100 \mathrm{kGy}$. 
Basing on the work of Willett and Shogren on starch foams (48), outer starch walls of holes formed during foaming by extrusion-thermoforming have burst, but to a larger extension in the starch mixtures herein studied. Consequently, trays from the mixtures became a little more brittle than those from unirradiated starch.

\section{Biodegradation of Foam Starch Trays by Mass Loss in Soil Burial Test}

Table 5 contains gain or loss mass of foam starch samples buried in soil during 42 days. The abrupt increase of the masses in the first seven days probably is due to water absorption from the humid soil, causing swelling of the original masses buried on the day zero. This period was taken as the lag phase of the biodegradation.

Table 5- Aerobic biodegradation under soil burial of foam starch trays molded from 1:1 mixtures by weight of unirradiated and $\gamma$-irradiated cassava starches at diverse radiation absorbed doses

\begin{tabular}{|c|c|c|c|c|}
\hline $\begin{array}{l}\text { Biodegradation } \\
\text { time }\end{array}$ & Mass gair & u loss $(g)-$ Mean \pm & Indard deviation & \\
\hline Days & BJ-St 0 kGy & Bj-St 25 kGy & Bj-50 kGy & Bj-100 kGy \\
\hline 0 & $2.4338 \pm 0.0340^{\mathrm{a}}$ & $2.1734 \pm 0.1059^{\mathrm{a}}$ & $2.1122 \pm 0.1877^{\mathrm{a}}$ & $1.7618 \pm 0.2536^{\mathrm{a}}$ \\
\hline 7 & $7.0485 \pm 0.0357^{\mathrm{a}}$ & $6.2583 \pm 0.2439^{b}$ & $6.0238 \pm 0.4572^{b}$ & $5.1018 \pm 0.4037^{c}$ \\
\hline 14 & $5.3035 \pm 0.1317^{\mathrm{a}}$ & $5.8382 \pm 0.1639^{b}$ & $5.6419 \pm 0.3653^{b}$ & $4.7334 \pm 0.4093^{c}$ \\
\hline 21 & $3.0780 \pm 0.9798^{\mathrm{a}}$ & $3.5335 \pm 0.2090^{\mathrm{a}}$ & $3.7016 \pm 0.2943^{\mathrm{a}}$ & $3.5452 \pm 0.3934^{\mathrm{a}}$ \\
\hline 28 & $2.7589 \pm 0.7914^{\mathrm{a}}$ & $3.3947 \pm 0.1477^{\mathrm{a}}$ & $3.5492 \pm 0.3494^{\mathrm{a}}$ & $3.4517 \pm 0.3444^{\mathrm{a}}$ \\
\hline 35 & $2.4924 \pm 0.6956^{\mathrm{a}}$ & $3.2725 \pm 0.0921^{\mathrm{a}}$ & $3.4736 \pm 0.2761^{\mathrm{a}}$ & $3.3539 \pm 0.2830^{\mathrm{a}}$ \\
\hline $42 *$ & $0.3127 \pm 0.0012^{\mathrm{c}}$ & $0.4510 \pm 0.0080^{\mathrm{b}}$ & $0.4943 \pm 0.0019^{\mathrm{a}}$ & $0.3109 \pm 0.0023^{\mathrm{c}}$ \\
\hline
\end{tabular}

* Note: On the 42nd day, samples were cleaned and weighed after drying at $70^{\circ} \mathrm{C}$ for $12 \mathrm{~h}$ up to constant weight. Different superscript letters in the row indicate statistically significant difference among the mean trays' masses along the biodegradation time according to one-way ANOVA test at $p<0.05$ and a confidence interval (CI) of $95 \%$.

The data sets exhibited in Table 5 were analyzed using one-way ANOVA test. The difference among the swollen foam tray samples was statistically significant on the 7th day of biodegradation: $F(3,4)=11.8719$ and $p=0.0185$, although Tukey's HSD post hoc test showed only a statistically significant difference between Bj-St $0 \mathrm{kGy}$ and $\mathrm{Bj}-\mathrm{St} 100 \mathrm{kGy}$ at $p=0.0137$. Similar fact occurred on the 14th day of biodegradation: $F(3,4)=10.0507$ and $p=0.0247$, and only a statistically significant difference between $\mathrm{Bj}-\mathrm{St} 0 \mathrm{kGy}$ and $\mathrm{Bj}-\mathrm{St} 100 \mathrm{kGy}$ at $p=0.0200$. On the 21st, 28th, and 35th day of biodegradation, the respective differences among the mean trays' masses were not statistically significant. Finally, on the 42nd day of biodegradation, the difference among the mean trays' masses was statistically significant: $F(3,4)=$ 961.7716 and $p=0.0000$, but highlighting that Tukey's HSD post hoc test showed only a statistically significant difference between Bj-St $25 \mathrm{kGy}$ and Bj-St $100 \mathrm{kGy}$ at $p=0.0002$, a $95 \%$ CI.

In turn, Figure 6 exhibits mean mass losses (in g) of starch foam samples, considered in absolute values, by biodegradation in soil throughout 42 days, time usually sufficient for total biodegradation of pure starch foams according to our assays of biodegradation in soil burial. The losses recorded every 7 days were computed from the weight differences related to the respective masses swollen to a maximum on the seventh day of biodegradation.

Formulations:

Type $15=$ unirradiated starch or Bj $-\mathrm{St} 0 \mathrm{kGy}$ 
Type $30=\gamma$ - irradiated starch at $25 \mathrm{kGy}$ or Bj-St $25 \mathrm{kGy}$

Type $31=\gamma$-irradiated starch at $50 \mathrm{kGy}$ or Bj-St $50 \mathrm{kGy}$

Type $32=\gamma$-irradiated starch at $100 \mathrm{kGy}$ or Bj-St $100 \mathrm{kGy}$

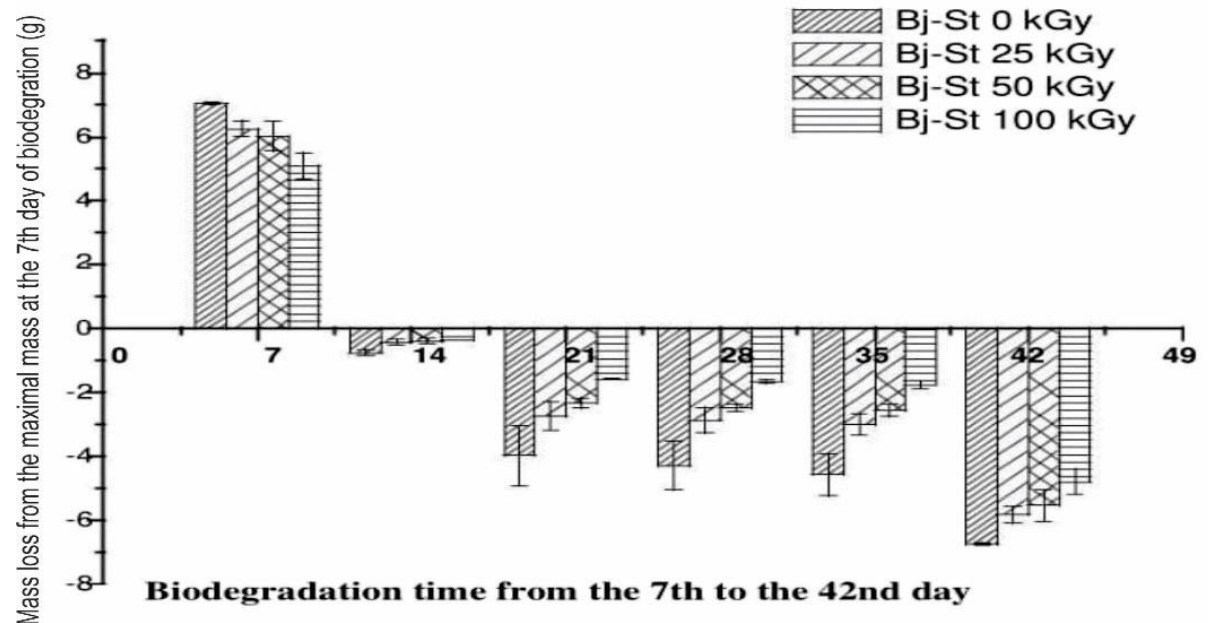

Figure 6. Aerobic biodegradation of starch foam trays by mass loss (in g) throughout 42 days. Samples kept buried in organic soil (ca. $60 \%$ moisture) at $20 \pm 1^{\circ} \mathrm{C}$, and at $74 \pm 4 \%$ external RH. Mass losses from the weight differences of the respective masses swollen to a maximum on the 7 th day of biodegradation.

During the first seven days, all the starch samples surely absorbed water from the humid soil gradually and swelled to a maximum (Table 5 and Fig. 6), thus increasing their original masses buried on the day zero of biodegradation, that is, mass gain: $189.6 \%, 187.9 \%, 185.2 \%$, and $189.6 \%$ for Bj-St 0 kGy, Bj-St $25 \mathrm{kGy}, \mathrm{Bj}-\mathrm{St} 50 \mathrm{kGy}$, and $\mathrm{Bj}-\mathrm{St} 100 \mathrm{kGy}$, respectively. It is due to high hydrophilicity of starch and glycerol. On the 21st day, abrupt mass losses in absolute values of all the samples were registered, and thereafter they continued to occur, but gently up to the 42nd day, inversely to irradiation dose. The mean mass losses (in \%) of samples formulated with $\gamma$-irradiated starches were slightly lower than those from the unirradiated starch, diminishing with increasing the $\gamma$-irradiation dose. This fact may characterize presence of crosslinked parcels in the irradiated polymer systems, which retard biodegradation $(49,50)$. The results either calculated or visually evaluated by photos (not shown) suggest that starch becomes less susceptible to biodegradation after being submitted to $\gamma$-radiation. However, in the case of probable prevalence of scission reactions induced by $\gamma$-irradiation on the polymer chain (Table 6, sample Bj-St 100 $\mathrm{kGy}$ ), biodegradation may occur at higher levels and shorter times. The mean results of actual mass losses of the starch trays on the day zero (in g) and on the 42th day (in $\mathrm{g} / \%$ ) of burial in soil are registered in Table 6.

Table 6- Mean mass loss (in \%) of starch foam trays made of $\gamma$-unirradiated starch and 1:1(w/w) mixtures of the latter with $\gamma$-irradiated starches at different radiation doses

\begin{tabular}{llll}
\hline Tray sample & $\begin{array}{l}\text { Initial mean mass } \\
\text { on the day zero }(\mathrm{g})\end{array}$ & $\begin{array}{l}\text { Mean Mass } \\
\text { on the 42nd day }(\mathrm{g})\end{array}$ & $\begin{array}{l}\text { Mean mass loss } \\
\text { on the 42nd day }(\mathrm{g} / \%)\end{array}$ \\
\hline Bj-St 0 kGy & 2.4338 & 0.3127 & $2.1211 / 87.15$ \\
$\mathrm{Bj}-\mathrm{St} 25 \mathrm{kGy}$ & 2.1734 & 0.4510 & $1.7224 / 79.25$ \\
$\mathrm{Bj}-\mathrm{St} 50 \mathrm{kGy}$ & 2.1122 & 0.4993 & $1.6129 / 76.36$ \\
Bj-St 100 kGy & 1.7618 & 0.3109 & $1.4509 / 82.35$ \\
\hline
\end{tabular}

Note: On the $42 \mathrm{nd}$ day, samples were cleaned and weighed after drying at $70^{\circ} \mathrm{C}$ for $12 \mathrm{~h}$ up to constant weight.

Evaluation of the results using this methodology is not a so easy task once starch is partially soluble in water and becomes tacky in the humid soil, where it can be eroded, solubilized, and / or hydrolyzed. Moreover, the specimens were not dried 
after being unearthed for cleaning and weighing, except on the 42nd day (samples cleaned and weighed after drying at $70^{\circ} \mathrm{C}$ for $12 \mathrm{~h}$ up to constant weight) (Table 5). Hence, a total removal of dirty material adhered to the samples has been almost impossible, what has hindered us to make a precise estimate of the actual mass losses of the samples. A mathematical treatment on the results was processed from the maximum swelling of the samples on the seventh day to values of the dry samples on the 42nd day. In this case, the biodegradation lag phase of the samples was taken as the first 7 seven days (from the day zero to the seventh day).

Table 7- Equations generated by linear regression (EGLR) from mean mass loss in biodegradation of starch foam trays made of mixtures $(1: 1$ by weight) of unirradiated and $\gamma$-irradiated starches at different radiation asorbed doses, whose samples were buried in soil during 42 days

\begin{tabular}{|c|c|}
\hline Foam tray sample & EGLR \\
\hline Bj-St 0 kGy & $y=8.209-0.185 x\left(R=-0.9571 ; R^{2}=0.9160 ; r s s=2.702\right)$ \\
\hline $\mathrm{Bj}-\mathrm{St} 25 \mathrm{kGy}$ & $y=7.479-0.15 x\left(R=-0.9412 ; R^{2}=0.8858 ; \quad r s s=2.504\right)$ \\
\hline Bj-St 50 kGy & $y=7.244-0.14 x\left(R=-0.9298 ; R^{2}=0.8646 ; \quad r s s=2.632\right)$ \\
\hline Bj-St 100 kGy & $y=6.235-0.115 x\left(R=-0.8897 ; R^{2}=0.7970 ; r s s=2.891\right)$ \\
\hline
\end{tabular}

Equations generated by linear regressions (Table 7) obtained from the data of mean mass losses of the samples buried in soil (Table 6) foresaw in these experiments the total biodegradation time of each foam tray sample: ca.44, ca.50, ca.52, and ca. 54 days for Bj-St 0 kGy, Bj-St 25 k Gy, Bj-St 50 kGy, and Bj-St 100 kGy, respectively. The results in Table 6 entirely corroborate this prevision or trend.

\section{CONCLUSIONS}

Mixtures of $\gamma$-irradiated starch - at radiation absorbed doses of 25, 50, and $100 \mathrm{kGy}$ - and unirradiated cassava starches to mold biodegradable foam trays, in general, have worsened the properties of barrier and those mechanical ones of the foamed product, displaying results of an increase of water absorption and a decrease of compression strength in comparison with those measured on trays made of only unirradiated cassava starch. Extrusion processability of the batters containing irradiated starches showed to be better than that of the batter containing only unirradiated starch. It is probably due to partial degradation and consequent lowering of molecular weights of the irradiated starches.

Aerobic biodegradation time by mass loss in soil burial slightly increased for the samples containing irradiated starch, maybe owing to small parcels of crosslinked polymer present in them, which slow down their biodegradation. In the continuity of this work, new trays will be molded by using in their formulations only unirradiated cassava starch and making use of reinforcements of fibrous biopolymers ( e.g. sugarcane bagasse or others) together with a glycolic plasticizer, water, and other additives if necessary. This procedure could enhance the physical properties of the foams. Even so, the finished product will be mechanically and chemically evaluated before and after sterilization by $\gamma$-irradiation, however, in this case, using radiation absorbed doses below $25 \mathrm{kGy}$, which supposedly do not compromise the structure of the polymer. 


\section{ACKNOWLEDGEMENTS}

The authors would like to thank the CNPq for research grants; CNEN / IPEN and BIO\&GREEN, where the tests for this work have been carried out. Special thanks to Charles Pereira da Silva for his collaboration in operating the extruder and thermoforming machine. The authors also declare no conflict of interest.

\section{REFERENCES}

1. Aberoumand A. Studies on Methods of Starch Modification and Its Uses in Food and NonFood Industries Products. World J. of Dairy \& Food Sci. 2011; 6, 115 - 124. http://www.idosi.org/wjdfs/wjdfs6(2)/1.pdf

2. Al-Assaf S, Phillips GO, Williams PA, du Plessis TA. Application of ionizing radiations to produce new polysaccharides and proteins with enhanced functionality. Nucl. Instr. Meth. Phys. Res. B; 2007, 37-43. https://www.researchgate.net/publicati on/229420339

3. Ames JM. Applications of the Maillard food industry. Food Chem. 1998; 62: 431439.http://www.sciencedirect.com/science/article/pii/S0308814698000788

4. Armentano I, Fortunati E, Burgos N, Dominici F, Luzi F, Fiori S et al. Processing and characterization of plasticized PLA/PHB blends for biodegradable multiphase systems. Express Polym. Lett. 2015; 9: 583-596. file:///C:/Users/Antonio/Downloads/EPL0005872article\%20(4).pdf

5. Atiq N., Ahmed S., Ali M. I., Andleeb S, Ahmad B., Robson G. Isolation and identification of polystyrene biodegrading bacteria from soil. Afr. J. Microbiol. Res. 2010;4:1537-1541. http://www.academia.edu/708990/Isolation_and_identification_o

f_polystyrene_biodegrading_bacteria_from_soil.

6. Avérous L., Fringant C., Moro L. Starch-Based Biodegradable Materials Suitable for Thermoforming Packaging. Starch/Stärke 2001; 53: 368-371. https://www.research gate.net/publication/205116896_Starch_Based_Biodegradable_Materials_Suitable_for_The rmof orming_Packaging.

7. Bahari K, Mitomo H, Enjoji T, Yoshii F, Makuuchi K. Radiation crosslinked poly(butylene succinate) foam and its biodegradation. Polym. Degrad. Stab. 1998; 62: 551-557. http://www.sciencedirec t.com/science/article/pii/S014139109800041X

8. Bao J, Ao Z, Jane J-I. Characterization of Physical Properties of Powder and Starch Obtained from Gamma-Irradiated White Rice. Starch/Stärke 2005; 57: 480487.http://citeseerx.ist.psu.edu/viewdoc/download?doi=10.1.1.465.559\&rep=rep1\&type=p df

9. Bertolini AC, Mestres C, Colonna P, Raffi J. Free radical formation in UV- and gammairradiated cassava starch. Carbohyd. Polym. 2001; 44: 269-271. http://www.sc iencedirect.com/science/article/ pii/S014486170000268X

10. Bhat R., Karim AA. Impact of Radiation Processing on Starch. Comp Rev Food Sci Food Safety 2009; 8:45-58. http://onlinelibrary.wiley.com/doi/10.1111/j.15414337.20 08.00066.x/pdf.

11. Brimhall B. Structure of pyrodextrins. Ind. Eng. Chem. 1944; 36: 72-75. http://pubs.ac s.org/doi/pdf/10.1021/ie50409a015

12. Byun E-H, Kim J-H, Sung N-K, Choi J-I , Lim S-T , Kim K-H et al., Effects of gamma irradiation on the physical and structural properties of $\beta$-glucan. Rad. Phys. Chem. 2008; 77: 781-786. http://www.sciencedirect.com/science/article/pii/S0969806X0700 4227

13. Cai W, Diosady LL, Rubin LJ. Degradation of wheat starch in a twin-screw extruder. J. Food Eng.1995; 26: 289-300. http://www.sciencedirect.com/science/article/pii/02 $6087749400056 \mathrm{~F}$

14. Charles AL, Chang YH, Ko WC, Sriroth K, Huang TC. Influence of Amylopectin Structure and Amylose Content on the Gelling Properties of Five Cultivars of Cassava Starches. J. Agric. Food Chem. 2005; 53: 2717-2725. http://dx.doi.org/10.1021/jf0483 76+.

15. Chmielewski AG., Saeid MH., Ahmed S. Progress in radiation processing of polymers. Nucl. Instr. Meth. Phys. Res. B 2005; 236:44-54. http://www.sciencedirect.com/scienc e/article/pii/S0168583X0500474X 
16. Chung HJ, Liu Q. Effect of Gamma Irradiation on Molecular Structure and Physicochemical Properties of Corn Starch. J. Food Sci. 2009; 74: 353- 361. http://onlinelibrary.wiley.com/doi/10.1111/j.1750-3841.2009.01159.x/pdf.

17. Cieśla, K. A., Nowicki, A., Buczkowski, M. J., Preliminary studies of the influence of starch irradiation on physicochemical properties of films prepared using starch and starchsurfactant systems. Nukleonika 2010; 55: 233-242.file://C:/Users/Antonio/Do wnloads/Preliminary\%20studies $\% 20$ of $\% 20$ the $\% 20$ influence $\% 20$ of $\% 20$ starch $\% 20$ irradiatio n\%20(1).pdf

18. Cinelli P , Chiellini E, Lawton JW, Imam SH. Foamed articles based on potato starch, corn fibers and poly(vinyl alcohol). Polym. Degrad. Stabil. 2006; 91: 1147-1155. http://www.science direct.com/science/article/pii/S0141391005003149.

19. Clough RL. High-energy radiation and polymers: A review of commercial processes and emerging applications. Nucl. Instr. Meth. Phys. Res. B 2001; 185: 8-33. http://www.sciencedirect .com/science/article/pii/S0168583X01009661

20. Coelho NS, AlmeidaYMB , Vinhas GM. A Biodegradabilidade da Blenda de Poli( $\beta$ Hidroxibutirato-co-Valerato)/Amido Anfótero na Presença de Microrganismos. Polímeros 2008; 18: 270-276. http://www.scielo.br/scielo.php?script=sci_artte xt\&pid=S010414282008000300014

21. Coutinho BC., Miranda BG., Sampaio G R, de Souza LBS, Santana WJ, Coutinho HDM. A importância e as vantagens do polihidroxibutirato (plástico biodegradável). Holos 2004; 3 : 76-81. http://dx.doi.org/10.15628/holos.2004.49

22. Dole M. The Effects of Ionizing Radiation on Natural and Synthetic High Polymers. J. Am. Chem. Soc. 1958; 80: 6694-6694. http://pubs.acs.org/doi/abs/10.1021/ja01557a 067

23. Ehrenberg L, Jaarma M, Zimmer EC. The Influence of Water Content on the Action of Ionizing Radiation on Starch. Acta Chem. Scand. 1957; 11: 950 - 956. http://actachemscand.dk/pdf/acta_vol_11_p0950-0956.pdf

24. Fredriksson H, Silverio J, Andersson R, Eliasson AC, Åman P. The influence of amylose and amylopectin characteristics on gelatinization and retrogradation properties of different starches. Carbohyd. Polym. 1998; 35: 119-134. http://www.scie ncedirect.co m/science/article/pii /S0144861797002476

25. Glenn G.M., Hodson SK. Fiber-reinforced starch-based compositions and methods of manufacture and use. US 7989524 B2 Patent, August 2, 2011. https://www.google.ch/p atents/US7989524

26. Gudmundsson M. Retrogradation of starch and the role of its components. Thermochim. Acta 1994; 329-341. http://www.sciencedirect.com/science/article/pii/0 040603194801002

27. Haghayegh G, Schoenlechner R. Physically modified starches: A review. J. Food Agric. Environ. 2011; 9: 27-29. http://world-food.net/download/journals/2011-issue_1/3.pdf

28. Hofreiter BT. Starch and Amylose Degradation by ${ }^{60} \mathrm{Co} \gamma$-Irradiation. J. Polym. Sci. A Polym. Chem. http://naldc.nal.usda.gov/download/2 9632/PDF

29. Kaisangsri N, Kerdchoechuen O, Laohakunji N. Biodegradable foam tray from cassava starch blended with natural fiber and chitosan. Ind. Crop Prod. 2012; 37: 542- 546. http://www.sciencedirect.com/science/article/pii/S0926669011003311

30.Kempner E S. Direct Effects of Ionizing Radiation of Macromolecules. J. Polym. Sci. B: Polym. Phys. 2011; 49: 827-831. http://www.ncbi.nlm.nih.gov/pmc/articles/PMC3 105523/pdf/nihms-289580.pdf

Received: August 02, 2016; Accepted: July 20, 2017 